\title{
РОЛЬ ДУХОВНОГО В ИЕРАРХИИ ЦЕННОСТЕЙ
}

\author{
Р.И. Амирова, Л.А. Медведева
}

Мир человека - это мир ценностей, а духовные ценности - это своеобразный духовный капитал, который на протяжении жизни человека не только не обесценивается, но и, как правило, должен возрастать. В истории человечества было несколько сменяющих друг друга установок, отражающих разные системы ценностей. Одна из наиболее древних - гедонизм. Его разделял ученик Сократа Аристип, который учил, что лучшая доля не в том, чтобы воздерживаться от наслаждений, а в том, чтобы властвовать над ними, не подчиняясь им. Позже к этой позиции склонялись Эпикур, Гоббс, Локк, Гассенди, Гельвеций, Гольбах и др.

Аскетизм идеалом жизни провозглашает добровольное отречение от наслаждений и желаний, культ страданий и лишений, отказ от благ жизни и привилегий. Эта концепция проявилась в христианстве, особенно в монашестве, в философских школах киников (Диоген с его девизом «быть нагим и одиноким»). Утилитаризм величайшей ценностью и основой нравственности считает пользу. По словам И. Бентама, смысл этических норм и принципов состоит в том, чтобы содействовать наибольшему счастью для наибольшего числа людей.

В XX веке учение о ценностях связано с именами таких выдающихся мыслителей и гуманистов, как А. Швейцер, М. Ганди, Б. Рассел, А. Эйнштейн, Дж. Сантаяна, Х. Ортега-и-Гассет и другими. Бурные социальные потрясения, появление возможности самоуничтожения человечества, возникновение глобальных проблем до предела обострили все традиционные проблемы. На первый план вышли общечеловеческие проблемы, связанные с признанием абсолютной ценности самой жизни человека и необходимости сохранить среду его обитания. Поэтому появление концепций «благоговения перед жизнью» (А. Швейцер), «заслужи любовь ближнего» (Г. Селье), «ноосферы» (В.И. Вернадский) и других не случайно, а отражает современный этап развития общечеловеческих идеалов.

Актуальні проблеми духовності

(Відп. ред.: Я.В. Шрамко)

Кривий Ріг (2005), 62-71 
В зависимости от понимания природы, сущности ценностей сформировались их объективистские и субъективистские концепции. Сторонники объективистской концепции считают, что источником ценностей является Бог, природа, культура (история). К субъективистской концепции ценностей можно отнести, прежде всего, психологизм - течение, представители которого определяют ценности через психологическое состояние субъекта. Свою концепцию ценностей, основанную на трансцендентальном сознании, предлагают неокантианцы В. Виндельбанд и Г. Риккерт. К сфере ценностей Кант и его последователи относили высшие ценности, которые возвышают человека над реальным бытием. На основе понимания ценностей, как того, что должно быть, они не считали ценностями материальные предметы, которые удовлетворяют потребности человека. Близкой к неокантианской является феноменологическая концепция ценностей (Э.Гуссерль). Э. Гуссерль и его последователи утверждали, что ценности конституируются (создаются) трансцендентальным субъектом, однако они образуют самостоятельную сферу, которая приобретает объективный характер.

Необходимо отметить, что среди философов и сейчас нет единого понимания ценностей и способа их бытия. Это обусловлено как разнообразием философских концепций, так и сложностью предмета исследования. Целью данной статьи является определение роли духовного в иерархии ценностей.

Согласно традиционной классификации ценности делят на материальные: одежда, продукты питания, техника и др. и духовные - моральные, религиозные, художественные, политические и др. Однако такое разделение не учитывает того, что в продуктах человеческой деятельности материальное и духовное взаимопроникают и чётко разграничить их невозможно. Например, трудно отнести египетские пирамиды или греческие храмы к материальным или духовным ценностям. Правильно было бы, наверное, вести речь о ценностях, которые удовлетворяют материальные или духовные потребности. Однако и такое разграничение не исчерпывает проблемы: куда в таком случае отнести такие ценности, как душевный комфорт, мир? Поэтому кроме ценностей, которые удовлетворяют материальные и духовные потребности, необходимо отдельно выделить психологические и социальные ценности, которые удовлетворяют соответствующие потребности. Например, переживания радости, счастья, душевного комфорта, к которым человек стремится и которые ценит, не принадлежат ни к духовной, ни к материальной сферам. Они являются душевными, а не духовными, ценностями. Социальные потребности также удовлетворяются соответствующими ценностями - такими, как социальная защищённость, гражданское общество, государство, церковь, профсоюзы, партии и др. Их также нельзя однозначно квалифицировать как 
материальные или духовные ценности. Однако на обыденном (бытовом) уровне вполне достаточным является разделение ценностей на материальные и духовные. При этом материальными ценностями (их иногда называют благами) считают экономические, технические и витальные (состояние здоровья, экологии) ценности, обеспечивающие телесное бытие человека, а духовными - религиозные (святость), моральные (добро), эстетические (прекрасное), правовые (справедливость), философские (истина), политические (благо общества) ценности, которые делают бытие человека человеческим, гарантируют его существование как духовного существа.

Значимость тех или иных ценностей в жизни человека не возможно установить без уточнения иерархии ценностей и роли духовного в ней. В обществе существует определённая иерархия ценностей, то есть среди всех ценностей выделяют ведущие и зависимые от них. Такая иерархия условна и зависит от исторической эпохи или типа культуры.

Исходя из роли ценностей в жизни человека их различают по содержанию: наслаждение, польза, власть, безопасность, красота, истина, добро, счастье, слава и т.д. По направленности ценности разделяют на положительные и отрицательные: наслаждение-страдание, польза-вред, славапозор, власть-подвластность, безопасность-опасность, красота-безобразие, истина-ложь, добро-зло, счастье-несчастье и т.д. Одни ценности принято относить к практическим, другие-к духовным. Ценности также принято разделять на высшие и низшие. Речь не идет, конечно, о том, что положительные ценности возвышенны, а отрицательные - низменны. Положительность и отрицательность определяется тем, отвечают ли ценности потребностям и интересам человека или нет. Для деления же ценностей на высшие и низшие необходим иной критерий. Различение возвышенного и низменного, духовного и плотского при кажущейся очевидности этих слов в обычной речи отнюдь не однозначно.

Один из возможных подходов к такому делению мы находим у Аристотеля - в его учении о благах. Благом, говорит Аристотель, называют то, к чему все стремятся. Но к одним вещам люди стремятся ради них самих, к другим - как к средствам для первых. Продолжая рассуждение Аристотеля, можно указать на то, что нечто привлекает и интересует людей как представителей какой-то профессии или какого-то сообщества, или как проживающих в определенной местности, или как имеющих некое хобби и т.д. Что-то интересно детям, что-то взрослым, что-то мужчинам, что-то женщинам. Однако должно быть что-то, что ценно для человека как такового независимо от половых, возрастных, профессиональных, религиозных, культурных и прочих различий. Не потому, что это что-то интересно возможно наибольшему числу людей, а потому, что это чтото не зависит от частных ситуаций и индивидуального стечения обстоятельств. То, что ценно для человека как такового вообще и отвечает его 
назначению, Аристотель называл высшим благом.

Методологически близкий к аристотелевскому, но содержательно существенно отличающийся от него подход к пониманию ценностей предлагается в том направлении современной философской антропологии, которое развивается в русле психоаналитической философии. Рассмотрим его на примере учения Э.Фромма. Фромм исходит не из предполагаемого предназначения человека, а из характера его существования. В отличие от животного, которое не обладает разумом, является частью природы и живет в гармонии с ней-человек, будучи частью природы, эмансипирован от нее и стоит вне ее, он наделен разумом, понимает свое бессилие, границы своего существования, свою смертность. Но человек - духовное существо, а значит, способен выходить за рамки самого себя, определять себя в ином, т.е. трансцендировать. Термин «трансценденция» традиционно используется в религиозном контексте и относится к выходу за пределы человеческих измерений, с тем, чтобы достичь переживания божественного. Такое определение трансценденции совершенно оправданно в теистической системе [2, с. 380$]$.

По мнению Фромма, как официально признанные ценности, так и фактически существующие не лишены структурности; они образуют иерархию, в которой некоторые высшие ценности определяют все прочие как соотносительные понятия, необходимые для реализации первых. Специфически человеческие переживания, развиваясь, формируют систему ценностей в рамках психодуховной традиции Запада, Индии и Китая на протяжении последних четырех тысяч лет. Пока эти ценности, утверждает Фромм, покоились на откровении, они были обязательны для всех тех, кто верил в источник откровения, под которым, насколько это относится к Западу, подразумевается Бог [2, с. 382]. Исходя из того, что ценности буддизма и даосизма основаны не на откровении верховного существа, можно сказать, что по этой причине буддийская иерархия ценностей доступна каждому, не имеющему никаких иных предпосылок, кроме рационального мышления и подлинно человеческого опыта. Применительно к Западу встает вопрос, может ли иерархия ценностей, представленная западной религией, иметь какое-либо иное основание, нежели божественное откровение.

Среди моделей, не принимающих божественный авторитет за основу ценностей, мы находим в итоге следующие:

1. Полный релятивизм, провозглашающий, что ценности - дело вкуса каждого человека, за пределами которого у них нет никаких оснований.

2. Признание того, что ценности - атрибут общества. Защитники этой позиции исходят из предпосылки, согласно которой выживание лю- 
бого общества с его собственной социальной структурой и противоречиями должно быть высшей целью для всех его членов, и, следовательно, нормы, способствующие выживанию данного общества, это высшие ценности и они обязательны для каждого индивида. С этой точки зрения этические нормы тождественны социальным, а социальные нормы служат увековечиванию данного общества, в том числе, его несправедливостей и противоречий.

3. Биологическая обусловленость ценностей, т.е. их имманентность биологической природе человека. Доводы некоторых представителей этого направления сводятся к тому, что такие переживания, как любовь, преданность, групповая солидарность, коренятся в соответствующих чувствах животных: человеческая любовь и нежность рассматриваются как ведущие свое происхождение от материнского отношения к детенышам у животных; солидарность-как коренящаяся в групповой сплоченности, характерной для многих животных видов [2, с. 383].

K сожалению, реальное материнство может быть и ущербным, и отклоняющимся. Но как социально-культурный (т.е. отраженный в представлениях и нормах) опыт материнства представляет собой отношения абсолютного бескорыстия и самоотверженной заботы. По логике своей роли мать стремится к тому, чтобы стать ненужной: ведь ее любовь и забота имеют целью подготовить ребенка к взрослой жизни и, стало быть, к независимости от такой заботы. Материнская любовь, несомненно, отличается от любви чувственно-эротической, которая стремится удержать любимого, сохранить его как любимого.

Однако взросление ребенка опосредствовано ослаблением и разрывом его связей с матерью, семьей (в смысле избавления от необходимости опекающей заботы). Условно говоря, преодолевая связь «дитя-мать», индивид обретает сознание, становится личностью, осознает различность между Я и Ты. С обособлением, с индивидуализацией усиливается личностное развитие человека. Обратная сторона автономии - изолированность, которая чревата одиночеством и отчужденностью. В мир взрослости ребенок почти неизбежно входит через врата одиночества. Но одиночеству и обособленности противостоит единение. Потребности в слиянии, единении с другими, в идентификации, стремление к стабильности в контактах с другими, говорит Фромм, суть основные из базовых потребностей человека. Развивая эту мысль, следует сказать, что, в конечном счете, полное удовлетворение этих базовых потребностей (реально редко осуществимое) воспринимается человеком как высшее благо, или идеал, которым и задается иерархия ценностей. 
Другое обоснование деления ценностей на высшие и низшие мы находим в рамках религиозного мировоззрения. В любой религиозной системе конечное предназначение человека усматривается в приобщении к Богу - обожании, через личное совершенствование и спасение. Высшие ценности - это ценности, посредством которых человек приобщается к Богу, низшие - такие, которые отвращают человека от Бога. Можно сказать по-другому: высшие ценности - это такие, посредством которых личность получает возможность трансценденции, выхода за пределы своего частного существования, возвышения над ним, низшие-такие, ориентируясь на которые, индивид погрязает в обыденности и суете, обрекает себя на духовное прозябание в потаканиях плоти. Иными словами, вопрос различения высших и низших ценностей - это вопрос духовного содержания жизни человека.

По мнению Э. Фромма, существует иерархия ценностей, в которой ценности более низкого порядка вытекают из высшей ценности, и что эти ценности являются обязательными и принудительно действующими принципами для практической жизни, как индивидуальной, так и социальной. В радикализме не исключены различия, зависящие от того, как утверждаются эти ценности в практике чьей-либо жизни, подобно тому, как существуют различия в христианстве и буддизме между теми, кто ведет монашескую жизнь, и теми, кто ее не ведет. Но все эти различия относительно несущественны в соседстве с принципом, согласно которому есть некоторые ценности, по которым компромисс недопустим. «Смею утверждать, - говорит Фромм - что, если бы люди действительно придерживались десяти заповедей или буддийского восьмеричного пути в качестве действенных принципов руководства в жизни, в нашей культуре в целом произошли бы кардинальные изменения. В данный момент нет необходимости спорить о деталях ценностей, которые нужно ввести в практику, куда важнее собрать вместе тех, кто согласен проводить принцип в жизнь, вместо, того чтобы подчиняться идеологии» [2, с.435].

На наш взгляд в иерархии ценностей, высшими ценностями можно считать те, которые основаны на том, что Альберт Швейцер назвал «благоговением перед жизнью». Швейцер формулирует свою аксиому: «Я жизнь, которая хочет жить, я - жизнь среди жизни, которая хочет жить» $[3$, с. 217]. Всегда, когда человек думает о себе и своем месте в мире, он утверждает себя как волю к жизни среди таких же воль к жизни. В сущности, Швейцер перевернул формулу Декарта, положив в основу самоидентификации человека не факт мысли, а факт существования. Его принцип, если пользоваться терминами Декарта, можно было бы выразить так: «Я существую, следовательно, мыслю».

Благоговение перед жизнью как высшая духовная ценность есть этика личности, она может реализоваться только в индивидуальном выборе. 
Швейцер считает, что этика перестает быть таковой, как только начинает выступать от имени общества. Общество не может не относиться к человеку как средству, не может не рассматривать людей в качестве своих исполнительных органов: оно неизбежно оказывается в ситуации вынуждающей оплачивать общее благо ценой счастья отдельных индивидов. Моральные апелляции и регламенты, которыми оперирует общество, по существу являются хитростью, предназначенной для того, чтобы добиться мытьем того, чего не удается добиться катанием, принуждением и законом. Поэтому этика личности должна быть начеку и испытывать постоянное недоверие к идеалам общества. И уж что ни в коем случае нельзя передоверять обществу, так это роль этического воспитателя, В этической критике общества Швейцер бескомпромиссен. Он говорит: «Гибель культуры происходит вследствие того, что создание этики перепоручается государству» [3, с. 229].

Ценным и благим считается все, что содействует более полному развертыванию специфически человеческих способностей и что поддерживает жизнь. Отрицательным или плохим является все, что подавляет жизнь и парализует внутреннюю активность человека. Все нормы великих гуманистических религий - буддизма, иудаизма, христианства, ислама или великих философов-гуманистов, начиная с досократиков и заканчивая современными мыслителями, представляют собой специфическую разработку этого общего принципа ценностей. Преодоление собственной алчности, любовь к ближнему, поиск истины (в отличие от некритического знания фактов) - вот цели, общие всем гуманистическим философским и религиозным системам Запада и Востока. Человек смог открыть эти ценности только по достижении определенного социального и экономического уровня развития, оставлявшего ему достаточно времени и сил для размышлений - исключительно о том, что находится по ту сторону чисто физического выживания. Но с тех пор, как этот пункт был достигнут, ценности утвердились, а до некоторой степени вошли в практику совершенно несопоставимых обществ - от мыслителей иудейских племен до философов греческих городов-государств и Римской империи, теологов средневековья, мыслителей Возрождения, философов Просвещения, вплоть до таких мыслителей индустриального общества, как Гёте, Маркс, а в наше время - Эйнштейн и Швейцер.

Ценности, которые называются гуманистическими, заслуживают уважения и внимания благодаря тому, что они единодушно приняты во всех высших формах культуры. Законы человеческого существования ни в коем случае не ведут к установлению одного набора ценностей в качестве единственно возможного. Они приводят к выбору, и нам предстоит решать, какой из альтернатив отдать предпочтение перед другими.

Но разве мы считаем вопрос решенным, когда говорим о «высших» 
ценностях? Кто решает, что выше? Например, ряд мыслителей утверждает, что любовь есть высшая духовная ценность. Шелер определяет любовь как духовное движение к наивысшей ценности любимого человека, как духовный акт, в котором постигается эта высочайшая ценность (он называет её «спасанием» человека). Шпрангер делает аналогичное замечание о том, что любовь «охватывает» потенциальные ценностные возможности в любимом человеке. По мнению В. Франкла: «Любовь, можно сказать, раскрывает перед нами ценностный образ человека. Делая это, она (любовь) совершает метафизический акт, поскольку ценностный образ, открывающийся перед нами в результате духовного подъема, вызванного любовью, является, по существу, „образом“ чего-то невидимого, нереального, точнее сказать, нереализованного» [1, с.260]. В духовном акте любви,-утверждает Франкл, - мы постигаем человека не только тем, что он «есть» во всей своей неповторимости и своеобразии, но также и тем, чем он может стать и станет (пользуясь старой терминологией, мы познаем его энтелехию). Давайте вспомним, говорит Франкл, определение человеческого бытия как возможности - возможности реализации ценности, реализации самого себя. «Поэтому любовь - это не более и не менее, как „возможность“ человека» [1, с. 260].

Осознание ценностей может только обогатить человека. Фактически это внутреннее обогащение частично составляет смысл его жизни. Таким образом, любовь, по мнению Франкла, неизбежно обогащает того, кто любит. Любовь открывает нам глаза на духовную сущность другого человека, на действительную природу его неповторимости, скрытые в нем потенциальные ценности. Любовь позволяет нам ощутить личность другого человека как целый уникальный мир и тем самым приводит к расширению нашего собственного мира [1, с. 261].

Ряд мыслителей утверждает, что высшей духовной ценностью является вера. Например, И. Кант справедливо подчеркивал, что вера не сводится к деятельности разума, о ней нельзя дать отчет исключительно на языке понятий. Вера есть некоторый смысл субъективного ориентирования человека в его предрасположенности к действию. Итак, вера один из наиболее значимых феноменов духовной жизни человека. Когда говорят о феномене веры, то часто утверждают, что он связан с невозможностью достаточных обоснований тех ценностных предположений, которые реализуются в вере. Здесь обоснование понимается чрезмерно узко, как нечто вроде рационального доказательства. Веру можно обосновать, но только для этого придется привести не только рациональные, но и чувственно-эмоциональные доводы. Эйнштейн как-то выразился в том смысле, что для него Бог - это вера в существование объективной реальности как независимой от человека. Вера - это тот мост, который связывает человека с миром. Это непременная характеристика личности, 
она требует веры в себя, веры, переходящей в уверенность в своих возможностях. Вера как ценностный феномен имеет свои градации, на высшей отметке мы находим идеал. Проблематика идеалов пронизывает всю нашу жизнь, её поверхностное прочтение приводило, приводит и, видимо, еще долго будет приводить к различного рода бедствиям.

Идеал - это, во-первых, наиболее общее, универсальное и, как правило, абсолютное нравственное представление о благом и должном, вовторых, образ совершенства в отношениях между людьми или - в форме общественного идеала - такое устроение общества, которое обеспечивает это совершенство, в-третьих, безусловный высший образец нравственной личности. Важным, на наш взгляд, является проблема соотношения идеала и реальности. В её решении можно выделить два основных подхода натуралистический и трансценденталистский.

При натуралистическом подходе идеал, во-первых, может пониматься как результат обобщения и абсолютизации в культуре того, что составляет предмет потребностей человека. Во-вторых, идеал может представляться результатом обобщения содержания норм и правил или отвлечения этого содержания от конкретных задач действия. В-третьих, идеал может пониматься как вытекающая из социальной или индивидуальной действительности ценность, раскрывающая перед человеком более обширные перспективы. Идеал сохраняет при этом образ совершенства. Это очень важно для миросозерцания человека, поскольку предъявляет ему требование самосовершенствования. Однако так понятый идеал оказывается сведенным к ценностной ориентации или поведенческой установке и также остается лишенным универсальных и абсолютных характеристик.

При трансценденталистском подходе к морали идеал рассматривается существующим как бы независимо от реальности и данным человеку непосредственно в его нравственном опыте. То, как он дан человеку, может трактоваться по-разному: как результат божественного откровения или интуитивного прозрения, как «голос совести» или сознание безусловного долга. Такая концепция идеала предполагает, что высшие моральные представления радикально противостоят реальности, должное противостоит сущему, а ценности - фактам .

Эти подходы, выраженные в соответствующих теориях морали, можно рассматривать как типологически различные. Они действительно противоположны в вопросе о происхождении идеала. Однако если рассмотреть их с точки зрения проблемы идеала в целом, то натуралистические концепции можно признать в качестве теории происхождения и становления идеала как формы ценностного сознания, тогда как трансцендентные концепции идеала-в качестве теории, представляющей логические и психологические аспекты функционирования идеала в ставшем виде, как ценности особого рода - универсальной. 
Стоит подчеркнуть, что независимо от того, каковы реальные истоки высших ценностей и идеала, они функционируют автономно по отношению к действительности - как действительности частных интересов социальных групп, ситуативно меняющихся ролей личности, различных профессиональных, статусных или функциональных обязанностей и т. д. Высшие ценности представляют собой часть духовного мира. Даже будучи обусловленными эмпирически в своем становлении и развитии, они безусловны в своем ставшем и развитом виде. Они выступают как закон, которому должен соответствовать эмпирический мир, как должное, которое вменяется сущему.

На этой абстрактной основе формируются абсолютные ценности, которые конденсируют глобальный общекультурный опыт. Неудивительно, что к ним принадлежат жизнь, здоровье, труд, общение, знания, самореализация. Но к ним же относятся и идеалы свободы, истины, справедливости, добра, красоты, в которых в гораздо большей степени отражен не столько прошлый опыт, сколько то, чего человечество не достигло. Эти идеалы устремляют нас к непокоренным вершинам. Они включают смертного индивидуума в общечеловеческое, вечное и бессмертное движение к будущему и тем самым, делают его бытие универсальным. За ними стоит мир значений и смыслов всей культуры. В спрессованном виде содержание ее воплотилось в высших духовных ценностях. Идеалы поэтому фиксируют общую направленность движения человечества от прошлого к будущему. В них ярко прослеживается направление и назначение духовности: ориентировать личность на будущее, на вечное. Благодаря идеалам человек не замыкается в рамках собственного бытия и материального благополучия. Он устремлен - вперед и выше.

Идеалы, выполняя роль смысложизненных ценностей, придают жизненному пути отдельной личности общекультурный смысл. Вместе с тем, они являются передаточным механизмом, с помощью которого новые поколения унаследуют от старших позитивный потенциал культуры. Они стержень, основа развития культуры. И вместе с тем, и это главное, благодаря им человек поднимается над серой обыденностью, над мелочным эгоизмом быта и приобретает подлинную духовность, возвышающую его и придающую ему черты ЧЕЛОВЕКА.

\section{1 Литература}

[1] Франкл В. Человек в поисках смысла.-М., 1990.

[2] Фромм Э. Психоанализ и этика. - М., 1998.

[3] Швейщер А. Культура и этика. - М., 1992. 